\title{
The resurgence of everyday experiences in school science learning activities
}

\author{
Anttoni Kervinen ${ }^{1}$ (D) $\cdot$ Wolff-Michael Roth ${ }^{2} \cdot$ Kalle Juuti $^{1} \cdot$ Anna Uitto $^{1}$
}

Received: 27 February 2019 / Accepted: 11 December 2019 / Published online: 21 January 2020

(c) The Author(s) 2020

\begin{abstract}
Science education can be alienating for students, as it is apart from the mundane world with which they are familiar. Science education research has approached the gap between everyday understandings and science learning largely as a challenge arising while learning about science concepts and the kinds of instructional approaches that may support this. However, the forms of everyday ways of relating to the world fundamentally expand beyond conceptual understandings. In this study, we use data from an outdoor science learning setting to examine a range of non-conceptual but culturally possible and intelligible ways in which students actually connect science learning processes to their everyday world and its characteristic commonsense understandings. Our study shows how students' (a) spontaneous embodied explorations, (b) humor in all of its bodily and grotesque forms, and (c) narrative representation and interpretation of the world are used to contextualize science learning, namely its environment and content, within their familiar world. We show how students draw on these fundamental cultural forms of understanding the world even without particular instructional support while, at the same time, completing their science tasks according to the goals set by their teachers. Our findings suggest that the ways in which students connect their everyday world with science learning do not have to be explicitly related to the particular conceptual learning goals but can parallel conceptual learning while contextualizing it in affectively meaningful ways.
\end{abstract}

Keywords Embodied learning · Everyday experiences $\cdot$ Interactional analysis $\cdot$ Humor · Narratives

Lead editor: C. Pouliot.

Anttoni Kervinen

anttoni.kervinen@helsinki.fi

Wolff-Michael Roth

mroth@uvic.ca

Kalle Juuti

kalle.juuti@helsinki.fi

Anna Uitto

anna.uitto@helsinki.fi

1 University of Helsinki, P.O. Box 9, 00014 Helsinki, Finland

2 University of Victoria, MacLaurin A567, Victoria, BC, Canada 
Students' experiences during learning-particularly how they connect to prior experiences-have been a persistent topic of science educational research. From a sociocultural perspective, previous mundane experiences have been theorized, for example, to be involved in the cultural border crossing between mundane and scientific understanding (Aikenhead 2001), reactualized in the social interaction in the classroom to understand the situation in scientifically relevant ways (Lidar, Almqvist and Östman 2009), or processed toward either unitary and monologic or open and dialogic forms of knowing (van Eijk and Roth 2011). Indeed, there is a fundamental connection between the historically and individually developed common sense of knowing one's way around the world and any new learning that occurs, even if the latter overturns the wisdom of the older and more fundamental common sense (Husserl 1989; James 1907). It is, therefore, not surprising to read that experiences prior to learning scientific content contribute to the formation of misconceptions (Vosniadou, Vamvakoussi and Skopeliti 2008). Insofar as different approaches underline the complexity of understanding the significance of (prior) experiences in science learning, the topic is all the more important. Research has repeatedly shown that a major reason for the difficulties of affiliating with science and science learning is that students do not perceive science as connected to their everyday lives, experiences, and cultural resources (e.g., Archer et al. 2010). There are gaps between mundane and scientific knowledge, even though the origin of the latter can be traced back to the experiences of the world in everyday life (Husserl 1989). These experiences are the premises from which knowledge is abstracted and passed on to subsequent generations. However, if the connection to the primal experiential premises is lost, there is a risk that scientific knowledge becomes valid "as a merely factual tradition [...] understandable only by those men who shared the same merely factual presuppositions of understanding" (Husserl 1989, p. 179). Based on a phenomenological orientation, this lack of a connection between scientific knowledge and mundane experience exists as a major challenge both in and to science education (Roth 2015).

Instructional approaches that contextualize science learning in terms of students' everyday experiences are suggested to both bridge the gap between their everyday lives and support science learning (e.g., Tsurusaki et al. 2012). Most studies of the connections between everyday experiences and science learning share two emphases. First, the connections focus on the conceptual level with regard to describing how the observed scientific phenomenon or concept is linked to experienced everyday phenomenon (e.g., $\mathrm{Na}$ and Song 2014). Second, even as students make spontaneous connections in their interactions, instructional guidance and scaffolding appear to be required for these connections to actually contribute to conceptual learning (e.g., Fleer 2009). However, experiences in a learning situation and how they are connected to everyday life expand beyond cognitive and conceptual dimensions, fundamentally integrating practical and affective dimensions of life (Roth and Jornet 2014). Experiences-past and presentare inevitably situated in the particular social interactions (Lidar et al. 2009), and the students' social interaction arises from the fullness of their lives instead of solely from the academic goals set by the teacher (Roth 2009). Little research exists at this time about the range and variety of cultural resources that are used to connect everyday life and learning sciences.

This study was designed to investigate how science learning situations come to be connected to students' everyday life experiences in ways that go beyond the conceptual dimensions. We draw on data from a biology unit in which eighth-grade Finnish 
students conduct field research in which students worked independently and out of earshot of the teacher.

\section{Theoretical background}

Research on the connection between everyday experiences and science learning takes a largely intellectualizing approach: The focus is on how the instructional approaches can help students to draw connections between their everyday lives and the conceptual world of science (e.g., Lidar et al. 2009). Although science learning inevitably has a strong conceptual character, the processes of learning - in addition to those making links to everyday experiences-involve the fullness of life along with its affective and bodily aspects (Roth and van Eijck 2010). The present study expands the scope of everyday experiences and their role in learning beyond the conceptual, cognitive, and linguistic dimensions through three non-conceptual dimensions of everyday understandings that are based on the works of mathematician and phenomenological philosopher Edmund Husserl, pragmatist psychologist and philosopher William James, philosopher and literature critic Mikhail Bakhtin, and philosophers and educators on the functions of narrative in the construction of cultural reality.

\section{Science education and students' everyday understandings}

A major challenge for science education today is the disconnect that students perceive between everyday (mundane) and scientific knowledge; this disconnect is often feels alienating for students and is one of the reasons for the declining interest in science and scientific careers (Barmby et al. 2008). A considerable amount of research has focused on the reasons for this alienation. It has been suggested that there is a gap between what many students experience in and how they perceive their everyday lives, on the one hand, and how science education in schools is presented and experienced on the other (e.g., Archer et al. 2010). Whereas out-of-school experiences are related to the students' interest in school science (Uitto et al. 2006), there is a sense that the familiar and everyday experiences of students are not sufficiently represented in science lessons ( $\mathrm{Na}$ and Song 2014).

Even though it appears as if scientific knowledge is separate from the everyday world, it is actually and fundamentally based on humans' everyday, mundane experiences in and of their world; the abstracted idealities are produced out of "what is given in the cultural world" (Husserl 1989, p. 169). Even in its abstracted forms, the process of science is very much a cultural process, and scientist themselves understand science as being socially constructed (Gilbert and Mulkay 1984). As Vygotsky (1978) and other scholars of sociocultural psychology have shown, this cultural world is social prior to individuals constructing it as such; the development direction of the thinking and understanding of the world is essentially from the preexisting social understanding to the individual one (Roth 2019). In addition, the anthropological approach to culture is social. Culture is conceptualized as the norms, values, expectations, and conventional actions of a group (Phelan et al. 1991). The fundamental importance of everyday sociocultural processes in understanding the 
world and producing scientific knowledge explains the various takes on the cultural dimension of science education. The common ground for these studies is to acknowledge that there is often a gap between science and the cultural conventions of the students, or, to put it another way, the cultural resources from which students draw in their everyday lives turn out to be inadequate to enable full participation in science education (e.g., Aikenhead 2001).

Connecting students' familiar everyday cultures and experiences with science learning has been shown to be a difficult task. From the cognitive perspective, incorporating students' everyday knowledge into science learning may be not only challenging but may also be considered harmful, as it is the origin of misconceptions (Vosniadou et al. 2008). Between everyday culture and science, there appear to be boundaries in place; so, learning means crossing cultural borders (Aikenhead 2001). Other research supposes that there are different spaces: The first space represents the home culture, the second space represents the scientific culture, and the third space is where the two are cobbled together (Gutierrez, Baquedano-López, and Tejeda 1999). In the third space, students' cultural resourcesfamiliar sociocultural and linguistic ways of participating in the community-are said to merge with scientific discourse to create a dialogic space within which students' everyday discourses and the official science discourse may converge in meaningful and authentic ways (Wallace 2004). In science lessons, students are said to (a) draw on various funds of everyday knowledge that is appropriated in the first space-such as knowledge acquired during interaction with family, peers, community, and popular culture-and (b) learn meaningfully by applying these funds (Moje et al. 2004). However, the construction of third spaces that foster meaningful connections in science lessons can be challenging, especially when the cultural backgrounds are diverse, and many studies emphasize the importance of considerable instructional support and guidance (e.g., Barton and Tan 2009).

The preceding shows that there is an emphasis on knowing. Indeed, most studies on the use of students' past experiences focus on how they draw on the conceptual and cognitive contents of their everyday experiences to support (or not support) learning and scientific understanding (e.g., Lidar et al. 2009). The translation of science knowledge into everyday experiences has been studied in terms of how the former enriches the latter (e.g., Pugh, Bergstrom, and Spencer 2017). Moreover, even if it has been recognized by previous studies that various familiar cultural resources are used in learning situations, and a number of studies have focused on instructional approaches that take leverage of cultural forms of relating to the world, such as narratives (e.g., Mutonyi 2016), few studies have actually investigated the spontaneous and ongoing processes by which students' everyday ways of understanding the world become the basis of science learning.

\section{Philosophical frameworks for the integration of science into everyday world}

Some philosophers place the foundation of understanding the world on the intuitive and self-evident facts from our lived-in world (e.g., James 1907). Accordingly, "in every individual life from childhood up to maturity, the originally intuitive life which creates its originally self-evident structures through activities on the basis of sense-experience very quickly and in increasing measure falls victim to the seduction of language" (Husserl 1989 , p. 165). The subsequent understandings are layered on this primary and fundamental 
evidence from sense-experience, which is the foundation of common sense. And although the new scientific knowledge occasionally undoes the previous forms of understanding, the very foundation of the experiential premises of understanding remain. For an individual, this experiential understanding forms the primal premises of meaning that "lie in the prescientific cultural world" (Husserl 1989, p. 172). Both Husserl and James trace the scientific understanding of the world, as abstract as it may be, back to these experiential premises. Because of the continuity of experience (Dewey 1934/2008), every new experience is based on, takes up, and transforms all prior experience. The origin of any scientifically conceptualized phenomenon is an individual experience in the world of everyday life, that historically and progressively transforms its meaning to a more conceptual or abstract form. As the experiential premise constitutes the foundation undergirding the logic of a given phenomenon and concept, learners of new epochs relive the conceptual idealizations that historically led to the first scientific idealizations (Husserl 1976). Otherwise, science would be merely logical and would have no connection to the world (Husserl 1989). For science education to build upon these experiential premises, a genetic approach has been suggested, emphasizing the primary experiential observations as the starting point of learning and the counterintuitive world of science remaining rooted within them (Roth 2015). The sentences in which scientific discipline is expressed "must be fixed and capable of being made self-evident again and again" (Husserl 1989, p. 177).

Husserl's way of thinking about the experienced world shares a similarity with James (1907), who suggests that our fundamental ways of thinking are based on a commonsense level of thought. The common sense is grounded in sense impressions that become rationalized by a set of concepts, such as "thing," "the same or different," "subjects and attributes," and "causal influences" (James 1907, p. 173). These commonsense categories specifically and the vast expanse of associated, generally invisible common sense become the foundation of our understanding of how the world works and the linguistic conceptualization of it. This is so because these conceptualizations

have been verified by the immediate facts of experience which they first fitted; and then from fact to fact and from man to man they may have spread, until all language rested on them and we are now incapable of thinking naturally in any other terms.

(James 1907, pp. 182-183)

Commonsense levels of thought may be separated from the scientific level of thought when science extrapolates to "invisible impalpable things; and the old visible common-sense things are supposed to result from the mixture of these invisibles" (James 1907, p. 185). However, the fundamental role of commonsense in our practical understanding of how the world works remains.

Both Husserl and James emphasize the foundational role of the body in experiential understanding, though they conceive of bodily character in a broader sense than mere physical interaction: "“[s]elf,' 'body,' in the substantial or metaphysical sense-no one escapes subjection to those forms of thought" (James 1907, p. 180). Indeed, bodily understandings are significant in students' conceptual understanding of science and in grounding their learning to their personal experiences (Roth and Jornet 2017). However, for the analytical purposes of the present study, the theoretical review of the bodily aspect of life must be further expanded from the point of view of a cultural historical dimension. 
An analysis of the works of French Renaissance author François Rabelais shows how a material bodily principle of life is a reference for situating and appreciating the world (Bakhtin 1984). The material bodily principle relativizes higher powers, authority, and authoritative knowledge (including that of science) by referring them back to the body, including humor and the grotesque. In science education, humor has been shown to assist students in appropriating science into the familiar worlds of their everyday lives (Roth, Ritchie, Hudson, and Mergard 2011) or overturn the authoritative dimensions of teaching (Kervinen, Roth, Juuti and Uitto 2020), whereas the grotesque in biology education can serve as a liberating moment and a resource for leveling the social hierarchies of science learning (Weinstein and Broda 2009). Bakhtin's analyses focus on the relationship that people have with the official, serious, and dogmatic institutional power and structures. During Rabelais's time, the carnival sense of life, humor, laughter, and the oaths and curses of the marketplace gave people "a temporary suspension of the entire official system with all its prohibitions and hierarchic barriers" (Bakhtin 1984, p. 89). This "second life" emphasizes the material, bodily aspect of life, "lowering of all that is high, spiritual, ideal, abstract" (p. 19) and serves as way to momentarily relativize the official seriousness and enter "the sphere of utopian freedom" (p. 89). Despite being joyous and of positive affect, this "second life" has a material, bodily, and grotesque character, and "[t]he people's laughter which characterized all the forms of grotesque realism from immemorial times was linked with the bodily lower stratum" (p. 20). Such forms, as one scientist's analysis of the role of humor in science shows, come with empathy - that is, with an affective involvement with the berated other or thing (Kilbourne 1996).

In addition to the bodily aspect of relating to the world-apparent in the form of common sense, as well as in relativizing humor and the grotesque-a third, non-conceptual dimension grounding the fundamental sense of understanding how the lived world works is the narrative representation of the experience and the world. In the narrative form, the fundamentally temporal character of human existence reaches language: "[T]ime becomes human to extent that it is articulated through a narrative mode, and narrative attains its full meaning when it becomes a condition of temporal existence" (Ricœur 1983, p. 52). The narrative discourse is not limited to the literate representations in fictive text and novels, but, like in the novel, narrative is "intimately interwoven with those direct changes in reality" (Bakhtin 1981, p. 7). Thus, narrative accounts inevitably involve the human world of action and experience, as "the narrative is part of a chain of speech by which a cultural community comes to be constituted and through which it interprets itself narratively" (Ricœur 1991, p. 131).

Being a characteristic form that enables humans to relate to the cultural world, narrative is significant for understanding the relationship between everyday life and science learning (Bruner 2004). Two modes of thought and of relating to the world may be differentiated: (a) science and scientific knowledge represent formal and logical forms of relating to the world, constituting a paradigmatic mode of thought, and (b) people use the narrative mode of thought to structure and explain their actions, motivations, and relationships through narratives. Even though there are also narratives and emotions in the world of science, the scientific knowledge is presented in a way that "attempts to fulfill the ideal of a formal, mathematical system of description and explanation" (p. 12). Because the narrative mode is the first and primary way for people to think and learn about the world, the perceived paradigmatic mode of thinking emphasized in science education abstracts and distances itself from the everyday lives and feelings of the people (Bruner 1986). Several studies 
suggest the inclusion of narrative elements in science education to close the gap between everyday narrative understanding and scientific explanations and language (e.g., Avraamidou and Osborne, 2009). The focus of these studies is primarily on the ways to use narratives and narrative explanations to communicate and advance understanding of science concepts and processes (e.g., Mutonyi 2016).

\section{Methods}

In this study, we investigate the ways through which students connect their everyday experiences with science learning processes. Students were accompanied on field trips during which they worked on biology learning tasks independently and out of the earshot of the teacher, which allowed for relatively free interaction and for the cultural phenomena to become particularly visible, thereby enabling them to be studied.

\section{Participants}

As a part of a research project on outdoor learning in Finnish schools, one teacher and two classes from one secondary school (grades 7-9) participated in the study. The particular school was selected for the research project because most of the ecology units in its biology courses consisted of fieldwork. The teaching followed the educational goals of the Finnish national core curriculum (Finnish National Board of Education, FNBE 2016).

Students from two-eighth-grade classes, aged 13-14 years (average 14 years), participated in the study. Based on the post-course group interviews, as well as informal discussions with the teacher, the students in the group from which the examples in this study were derived were not very science-oriented and perceived the assessment as an important factor motivating them to complete the tasks well. Because it has been shown that talking about science and technology is a sociocultural phenomenon irrespective of individual characteristics (Roth 2013), knowing the individual characteristics of the particular students is not important for this study. Here, for our analyses, we take the sociological stance that Roth proposed in this journal.

During the fieldwork for the eighth-grade biology course, the students worked in an urban forest park area near the school. The first part of the course (eight lessons) consisted of small tasks and inquiries into the ecological phenomena in the forest. The lessons usually started with an introduction (5-10 $\mathrm{min}$ ) in the classroom before walking for 5-10 min to the nearby urban forest area. The students worked in groups of three or four and moved independently in the forest, most of the time without the direct presence of the teacher, to complete the tasks (e.g., observing and identifying plants and abiotic factors, such as light and soil in a chosen spot; observing different habitats; and finding and identifying mushrooms or invertebrates). Depending on the task, they provided the teacher with brief reports at the end of or during parts of the lesson through photographs and mobile messages. The teacher moved around between different groups or remained stationary, communicating via whole-class mobile messages. The latter part of the course (eight lessons), which entailed working in the same groups, consisted of a larger inquiry based on students' own research questions. There were single, 45-minute and double, 90-minute periods, which affected the contribution of the tasks and some other pedagogical arrangements between the two classes. Most of the small tasks were evaluated, and each contributed $10 \%$ 
to the final grade, whereas an individual plant-collecting task and a larger group inquiry represented a larger contribution of $20 \%$ and $30 \%$.

The teacher had a master's degree and 30 years of experience teaching biology and geography at Finnish secondary and upper secondary schools. For over two decades, she had been developing biology curricula with an emphasis on outdoor teaching. The pedagogical choices of the outdoor intensive model that was used are described in more detail elsewhere (Kervinen, Uitto, and Juuti 2018). The teacher briefly emphasized the trusting and positive relationship between her and the students as well as students' sense of freedom, whereas the structural components, such as regularity of fieldwork and ongoing assessment practices, were needed to justify and present the activities to students as real schoolwork. The teacher argued, in accordance with the national core curriculum (FNBE 2016), that authentic interaction with the natural environment encourages students to make observations and engage in thinking that promotes relevant ecological understanding. Simultaneously, the freedom of the students contributes to a pleasant experience for students that supports a positive relationship with nature.

\section{Data collection and analysis}

The data sources used in the study include video- and audio-recorded lessons of two groups of four students, field notes, and group interviews of the students after the course. For the video recordings, two handheld cameras were used. The audio was recorded using external microphones for each student and the teacher; this allowed the videos to be recorded from some distance, thereby interfering minimally with the students' activities. During the group interview after the lessons, the students were asked about the presence of the researchers and video recording. They reported that they had quickly forgotten about the recording and that it, thus, had no effect on their activities. For example, in the group interview, when the students were shown short clips of the video data, they laughed upon realizing that all of their conversations had indeed been recorded. All agreed on that the recording had no effect; for example, Mark stated that he "completely forgot the recording at some point in the beginning," and Max confirmed that "as you could see, we didn't talk particularly nicely there." According to these repeated remarks from the students themselves, it is justifiable to assume that the recording and the relatively distant presence of the researchers did not influence the students' interactions in a way that significantly changed its content or altered the atmosphere from what it would normally have been.

The video and audio recordings were synchronized before the analyses. Raw transcripts of the lessons were produced using Transana 3.10 software. The episodes that were selected for the in-depth analyses were subsequently transcribed using a conversation-analytic system (Selting et al. 1998). The transcription conventions used are explained in Appendix. The conversation among the students originally took place in Finnish, and the fragments presented in this paper are translations (with the exception of occasional English words, which are underlined in the transcriptions). The translations were done with the aim of capturing the original unofficial tone of the spoken language. The translated idiomatic remarks are further explained in brackets. The translation was first done and agreed upon by three native Finnish speakers, after which it was checked by a native English speaker. 
The analyses reported in this study are based on the interactional analysis of students' interactions (Jordan and Henderson 1995). First, the important themes were identified from the data sources. The samples from the selected lessons were analyzed interactionally in joint data sessions. Based on the discussions on the emerging sense of what is happening in the samples, we formulated tentative hypotheses based on the studied phenomena. We then scoured the entire video database to find evidence that either disconfirmed or was consistent with the tentative hypotheses (Roth 2005). The emergent understandings generally and any alternative understanding in particular were discussed during repeated meetings, and the present report is the result of this iterative process of joint analysis, writing, and discussions.

In the analyses, we attempt to produce and provide an adequate account of the students' interactions that we observed. The minimum unit of analysis that makes sense for analyzing this interaction is a pair of communicative turns. This is so because the value of an utterance in and to a conversation is tied to its social evaluation, which the listeners make available for the analysis in their own turns that follow immediately (Vološinov 1973). Thus, the nature of the unfolding social interaction can be analyzed based on the ways in which the utterances are reacted and responded to in the particular interaction. This approach does not require special interpretive methods; rather, the analyst is required to hear the participants in the manner in which they hear and understand each other (Garfinkel and Sacks 1986). In our report, we make visible how the unfolding interaction can be heard, as well as the possible (general) cultural premises on which our understanding is based.

In the following sections, students' interactions in the selected episodes are analyzed in this manner to show the ways in which their everyday experiences are brought into science learning. Because the everyday understandings focused on here constitute culturally characteristic and interactional phenomena- a cultural historical (Bakhtin 1984), phenomenological (Husserl 1976), or narrative point of view (Ricœur 1983) - they constitute cultural possibilities rather than phenomena that are specific to individual students. They are, in fact, observed across the course with several students but are highlighted in the selected episodes with particular students.

\section{Findings}

This study was designed to investigate how students connect their everyday forms of understanding the world with science learning in ways that expand beyond the conceptual thinking of both experiences and learning. The research question is investigated in a fieldwork science context in which the students could interact relatively freely with the environment and each other many times out of the earshot of the teacher. In the following three subsections, we show how the students spontaneously connect the learning process with their everyday experiences in ways that draw on fundamental bodily and cultural forms of relating to the world: (a) how students explore the physical environment through embodied interactions, (b) how grotesque and bodily humor is used to relativize the seriousness of science learning into a more relatable level, and (c) how narratives serve as a way to contextualize learning tasks within the familiar cultural resources. 


\section{Embodied explorations of the environment}

Body and bodily interactions with the environment play a major role in our primary understanding of the world and constitute the foundation of our common sense (Husserl 1976; James 1907). Accordingly, the embodied interactions are shown to be significant in students' conceptual understanding of science, as well as in grounding learning to their personal experiences (Roth and Jornet 2017). In this section, we show how both task-related and spontaneous physical interactions with the physical environment provide students with means to contextualize science learning as part of their living bodily experiences in the surrounding world.

In this study, students actively interacted with the physical environment over the course of all the recorded lessons. Some of the interaction was related to and required by the tasks themselves, such as when the students were digging in the soil, moving and looking under logs while searching for invertebrates, or handling mushrooms. Conversely, some of the interactions were not directly task-related - that is, not directly needed for completing the task-but nevertheless occurred while completing the tasks. These activities were many times accompanied by discussions that made connections to everyday life outside the school and science lesson. For example, the students picked up sticks and played with them (e.g., throwing a javelin), threw around mushrooms (imagining them as being something else), kicked and hit tree trunks (practicing martial arts), and picked blueberries (as could also be done "after school").

Some of these spontaneous activities turned out to have value as explorations by means of which students gathered scientifically relevant knowledge. Whether or not the knowledge gained from the observations was related to the task was, therefore, unknown while it occurred. For example, after making some required observations of a particular sampling spot in the forest, the students investigated whether a spider would react to a stick touching its web. After losing the spider, which had dropped to the ground, the students spent time digging and mixing the soil, trying to find the spider and "his brother." Moments later, the same holes that had been dug in search of the spiders were used to conduct task-related observations of the soil. The following fragment was recorded during another spontaneous bodily exploration, which began without an initially apparent purpose for science learning and was later used to complete a required task. In the fragment, the group was visiting an area of investigation that had been assigned to a different group. The objective was to exchange the ideas about previously observed characteristics (such as vegetation, soil, and abiotic factors) with another group. Before the hosting group started describing its sampling area, the students started to discuss the possibility of felling a dead tree. 


\section{Fragment 1a}

John: well here's our spot

2 Tom: no but what else (.) can you fell a tree ((pushes a dead tree with his foot) )

3 John: Jim has tried, but he couldn't do it

4 Tom: well Jim he couldn't cut this down for sure

5 Mark: why don't we fell this [fuck just for fun]

6 Max: [for sure I could] fell this, but

[don't wanna now]

7 Tom: [you could fell this]

8 Tom: at the summer house, it's fun to fell these (.) here ((unclear))

9 Max: check this out (.) check this out ((knocks the tree with a small shovel)) (..) well it doesn't break that [easily] ((laughter))

10 Mark: [wait give] me that

( (takes the shovel))

11 Tom: ((leans on the tree)) no but you have to get some speed ( (Max and Mark both kick the tree))

12 John: we go to your spot (.) thank you ((the other group is leaving))

13 Max: yeah fuck ((unclear))

14 Tom: no but you have to wave it to the beat of the [rhythmic music]

15 Max: [no it's not] all

rotten

16 Mark: it's not all rotten ((keeps on knocking the trunk)) (..) from up there (.) it's much more rotten

17 Max: it's quite tall

18 Mark: quite tall

Mark: ((knocking the tree with the shovel))

I've observed (..) the hardness of the

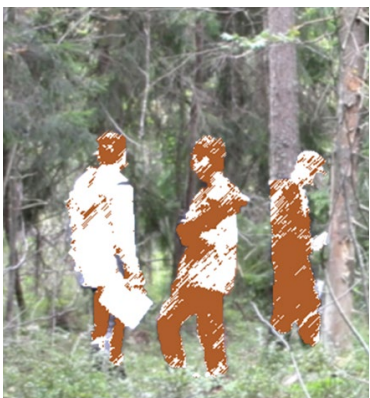
tree 
At the beginning of the fragment, John introduces (as a response to a request to say something about the spot) the spot without giving any information required by the task. Tom responds with what can be heard to be some form of disagreement with John's statement ("no, but what else"). Without waiting for elaboration, he turns his attention to a tree and raises a question about felling it. The students discuss whether it is possible to fell the tree, and Mark suggests trying it (turn 5). Tom states that felling the trees is fun "at the summer cottage" (turn 8), referring to his or someone else's experience of a similar endeavor elsewhere. The students then discuss the felling while continuing their physical explorations (turns 9-14 and onward). The tree does not fall, but the students do not appear to be too disappointed or serious about it; instead, they are laughing. Max and Mark make observations about how rotten and tall the tree is (turns 15-18). Sometime later (offprint, turn 24), Mark states explicitly that he has made an observation regarding the hardness of the tree. The pertinence of the observation to their assigned task is not made apparent in that instance but comes into play a little later.

Soon, the students raise the question of what they are supposed to do, and they consult the instructions and remember that they are to make observations of their areas of investigation. Tom asks the question about what there is, and the following discussion then takes place.

Fragment 1b

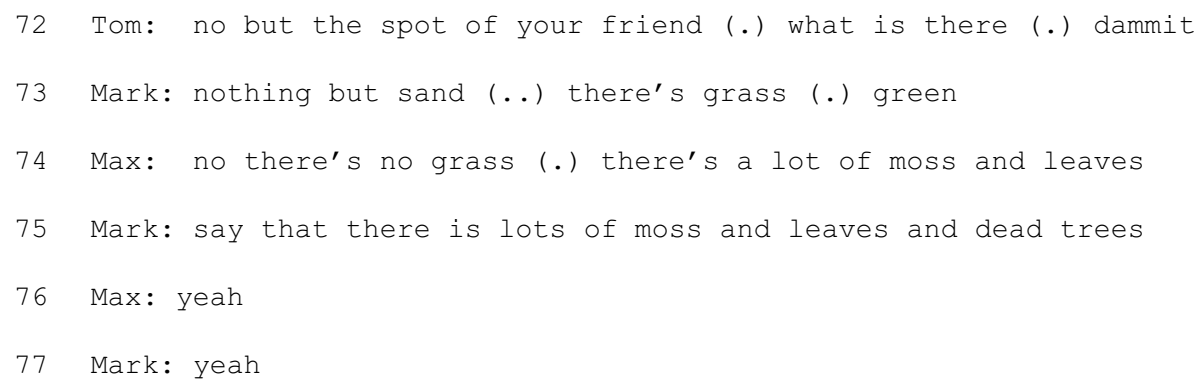

Mark responds to Tom's question (turn 73), stating that there is nothing but sand and continuing with a description of "grass" and "green." With the next turn, Max disagrees with Mark's notion of grass, stating that that there are leaves and moss instead, which is something of a more accurate description of the vegetation and the ground texture. Mark then addresses Tom, who has previously written out the answers, repeating the notion of moss and leaves, adds "dead trees." Max and Mark later accept the expanded description (turns 76, 77). We cannot know whether the addition of "dead trees" by Mark would have been made in the absence of the earlier explorations with the dead tree and "observing the hardness." However, the fragment shows how the physical exploration that might initially have appeared as off topic and play is connected to science learning a few minutes later. The scientific observation is here contextualized in the immediately preceding bodily experiences. This is so even though 
the preceding experiences were of a non-teleological and spontaneous nature and were seemingly unrelated to science learning. However, the abstract concept denoted by the term "dead trees" is now grounded in the experience of whether a dead tree can be felled and how rotten it is when knocked with a shovel. This experiential understanding of the dead tree becomes the primary premises of meaning that "lie in the prescientific cultural world" (Husserl 1989, p. 172). Thus, when, a moment later, the students provide the concept of "dead trees" in the paper as an answer for their scientific task, the original experience is transformed to the conceptual form, and "the language is rested" on this commonsense foundation that is acquired by the bodily experimentation with nature (James 1907, p. 183).

In the analyzed episode, the spontaneous bodied experimentation was initially inspired by a curiosity of knowing whether the tree could be felled. However, as was shown shortly thereafter, the activity (and later the concept of "dead trees") was contextualized within not only the physical surroundings but also life at the summer cottage, where felling trees was also "fun." Whether it was the physical environment itself or the prior experiences related to it that inspired the bodily exploration in the first place could not be discerned from the data here nor from many of the other abovementioned examples; they were intertwined in the manifestation of the bodily activity. Nonetheless-and whether the activities explicitly turned out to be used later in the science task-the continuous bodily experimenting functioned as a way to relate to the familiar lifeworld. Even if the prior experiences would not have been explicitly brought out, this would be the case from a more general point of view of the everyday understandings; as the intuitive and self-evident sense experiences lay the fundamental foundation for relating to the world and common sense (Husserl 1976; James 1907), the activities of bodily exploration per se constitute the familiarity of the everyday world for the students.

\section{Relativizing science learning and context through humor and the grotesque}

In science education, grotesque humor, exaggeration, and abasement may provide means for students to overturn the seriousness of science and thereby appropriate it into their familiar lifeworlds (Roth et al. 2011; Weinstein and Broda 2009); humor not only functions to establish interpersonal relations but also allows students to engage with the disciplinary discourse and local norms of science (Berge 2017). In a humorous and grotesque sense of life, the material bodily principle is manifested as a reference for relating to the world and temporarily overturning the official prohibitions (Bakhtin 1984). In this subsection, we focus on the students' articulation of the grotesque, which is often associated with bodily laughter, to show how the humorous dimension of students' interaction has a function to connect serious science learning and the mundane perceptions of life.

Humor, jokes, ridicule, and laughter in the interactions among the students were abundant during the lessons; this phenomenon was possibly enabled by the absence of the teacher from the immediate environment. There are many instances in which laughter occurred in the middle of a learning task; it arose from an observation or 
interaction with the environment or a drawn connection to some everyday phenomenon, such as imaginary hunting or thinking about using poisonous mushrooms for the purpose of intoxication. The language and joking also had a vulgar and ridiculing dimension and were often linked with the lower bodily stratum. Previous Bakhtininspired forms of analysis showed that this kind of grotesque and bodily humor may function as a way to relativize the seriousness of the official task of learning science and allow students to temporarily contextualize the learning experience on their own terms, drawing from the experiences and lifeworlds that are meaningful to them (Roth et al. 2011; Weinstein and Broda 2009). The following fragment shows how two instances of such humor arise in the middle of the science task and how they are used to relativize the seriousness of science. While the content of the language and some expressions can be considered offensive and disrespectful, especially due to the use of culturally taboo words related to sexual intercourse or sex organs (cf. Ljung 2011), our analysis focuses on the humorous meanings perceived and explicated by the students, as well as the functions that the grotesque and bodily humor have in the middle of the science learning task. The particular fragment was chosen for the exemplification of these functions because of the students' particularly explicit notions of the temporality in their ability to make grotesque and offensive jokes while working out of the earshot of the teacher. A moment earlier, the students had found ants and ant eggs under the rocks. After turning another rock over, they had discovered yet more ants of a different, much bigger species than what they had found previously. After providing several notions of the size (accompanied by screaming) and placing some ants and eggs into jars (accompanied by repeated requests and encouragement from each other), the following discussion took place. 


\section{Fragment 2}

26 Mark: those are so cool

27 Max: dammit (.) I got frightened when there were so many of those and they were so like

28 Tom: there're so many ant eggs

29 Mark: yeah

30 Tom: let's take a picture of that so Krista

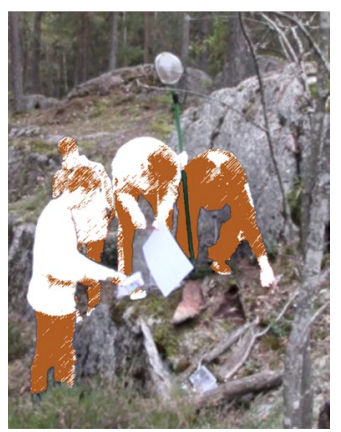
gets an orgasm

36 Mark: ((to Max)) let's take a picture of that so Krista gets an orgasm ( (Jeff and Mark laugh))

37 Max: wou

38 Mark: that was a little too much fuck ((laughter)

39 Jeff: yeah (.) Tom ((laughter))

40 Mark: huh huh

41 Tom: I apologize ((everyone laughs))

42 Jeff: apologize ((laughter)) (..) look they are there hiding [just watching over there]

43 Max: [well if we're totally] honest it was quite funny really

44 Mark: well yeah ((laughter)) (.) but still it was a little too much though ((laughter)) (.) is this (.) can you lift this ((tries lifting a rock)) (..) no

45 Jeff: let's go find more

46 Max: under the rocks

47 Jeff: ((looking into the jar)) look what this one does; it took it into the mouth

48 Mark: rocks are the way to go

49 Tom: there's an egg (.) in its mouth

50 Mark: oh fuck ((laughter))

51 Max: it sucks dick ((laughter)) ((in Finnish the words "egg" and "dick" are the same in this instance)) 
Mark (turn 26) and Max (turn 27) state how the ants are "cool" and that finding them was an emotionally strong experience ("got frightened"). These utterances can be seen as suggesting that the students found the situation exciting and that it aroused positive affection (also implied by the earlier screaming and laugher and the later statement that the task was "fun"). After once more addressing the ant eggs (turn 28), Tom then suggests taking a picture of the ants so that their teacher "gets an orgasm." Because in the previous lesson the students have taken pictures of identified mushrooms and sent them to the teacher for evaluation, Tom's suggestion can be seen as implying that the picture should also be sent the picture (Tom actually takes the picture a moment later but never sends it). Mark repeats the utterance to Max (turn 36), who had been discussing something else and had not heard the original words. The reactions to Tom's suggestion are accompanied by laughter (Jeff and Mark). Laughter is not randomly produced as an interactional resource but, like other forms of parody, can be understood as (a) a salient invitation for others to laugh and (b) as the recognition and acceptance of that invitation (Jefferson 1979). Thus, the laughter, in this instance, can be viewed as turning the suggestion into a humorous one. The "wous" and "huh huhs" can be heard as markers that something has been said unexpectedly. Mark states that what Tom said about the taboo theme related to sexual intercourse was a "little too much," which is accompanied by laughter. Jeff then agrees with Mark's comment about the suggestion being a "little too much," and he also laughs. Tom then apologizes, which is responded to with laughter from the others, thereby implying that it is not being treated as serious nor as an apology. Max's utterance (turn 45) explicates the tension between disapproving of Tom's suggestion and being "totally honest" and accepting of it as "quite funny really." Mark, saying and laughing that it was "a little too much though," also accepts the humor in the original suggestion. He then tries to lift another rock. Jeff, Max, and Mark talk about finding more ants under the rocks (turns 45, 46, and 48); they thereby exhibit focus on the task. The students observe an ant carrying an egg in its mouth, the description of which is treated with laughter (turn 49). The students are playing with and finding humorous the double meaning of the Finnish word "egg." The observation of the ant unfolds in a humorous manner ("it sucks dick"), and there is repeated laughter after the taboo words, which were once more related to sexual intercourse (cf. Ljung 2011). After this, the students continue to look for other rocks to lift.

In the fragment, the students' engagement in science and the (serious) effort to complete the task are manifested in a commitment to observe and collect ants and in the expressions of the positive affect (e.g., "let's go find more," "those are so cool"). The students work in line with the science learning goals of the lesson, recognizing different ant species and observing where they dwell and lay eggs. Simultaneously, they draw on grotesque and offensive jokes by using the words and expressions related to taboo themes that are typically considered swearing (cf. Ljung 2011). The sense of taboo and disapproval was even noted by the students themselves as they at times recognized the expressions to be a "little too much" and as a reason to (ostensibly) apologize. As this study focuses on cultural ways - grotesque humor, in this instance — to make connections with learning and everyday life, it is out of our scope to examine the (youth) cultural framework behind the language and content of the jokes. What is important is that, for the students, these questionable expressions were explicitly humorous, "fun," and accompanied by laughter and excitement. The purpose and function of grotesque humor, manifested in the jokes related to the lower bodily stratum, serve as a way for people to relativize and lower the abstract and spiritual to the material and bodily level, where the elevated and ideal (temporarily) becomes relatable and controlled by the people (Bakhtin 1984). Thus, "the essential principle of grotesque realism is degradation, that is, the lowering of all that is high, spiritual, ideal, abstract; 
it is a transfer to the material level, to the sphere of earth and body in their indissoluble unity" (pp. 19-20). Accordingly, the humor of the students and particularly its bodily and grotesque aspects contextualize their science learning experience in terms of what they can relate to and what makes sense to them in their everyday world and its material bodily level. What might otherwise be perceived as serious, official, and abstract science learning can, thus, be "degraded" through the grotesque realism of life-for instance, connecting the task content or context with taboo themes or words.

The degradation and relativization, however, are neither permanent nor exclusive; they do not hamper the students' commitment to the science task. Indeed, as the commitment to the task was simultaneously manifested in their actions and talk, the degradation is reversed and is subservient to the serious pursuit of science. This double function of the humor is denoted by the term "carnival sense." The carnival sense of life occurs only momentarilyas in the European and Brazilian carnivals - and its "legalization was forced, incomplete, led to struggles and new prohibitions" (Bakhtin 1984, p. 90). In this study, too, the students-during and after their joking-complied with the seriousness of the task and continued it (e.g., collecting invertebrates or making and writing observations). The fact that the students recognized the offensive and prohibited tones of their joking underlines how the degradation was only temporarily allowed by the absence of the teacher and thereby the official disciplinary restrictions. As the absence of the teacher allowed their joking to remain within the sphere of students' mutual interaction, they did not directly defy the serious, institutional, and authoritative dimensions of the teacher's position (and that of science); the temporary carnival sense of the joking allowed the degradation of the authority to happen while the authority did not lose its power in a way that would have posed any actual problem in the interaction between the teacher and the students.

\section{Using narratives to frame learning}

Narrative is a characteristic way for humans to articulate the cultural reality and relate to it (Ricœur 1983). In contrast to the narrative mode of thinking, science and scientific knowledge are often perceived to represent formal and logical forms of relating to the world, abstracting, and distancing itself from everyday life and the feelings of the people (e.g., Bruner 2004). Narratives have been shown to have potential in communicating science and explaining scientific phenomenon in ways that are relatable to students (Avraamidou and Osborne 2009). In this section, we show how students spontaneously draw on the narrative mode of thought at multiple levels to connect the science learning tasks with their everyday lives; they draw from cultural narratives from their out-of-school lives to contextualize the learning tasks and frame their own activities as a narrative of which they are part.

The narrative mode of thought appeared on multiple levels of the students' interaction. First, students repeatedly invoked narrative elements when describing their actions, observations, or experiences during the tasks; these were either related or not related to the completion of the task. For example, (a) when encountering a dead bird, the students referred to an imagined fight between a bigger and a smaller bird; (b) when finding poisonous mushrooms, reference was made to an assumed story of foolish people using them for intoxicating purposes; or (c) while trying to see whether a spider reacted to the touch of the web with a stick, a parallel story was told about humans having to cope with someone destroying their homes. The students also connected their experiences of being in the particular environment (i.e., the forest) in terms of their pastime experiences with narrative dimensions, such as perceiving a place as being good for "having a break and enjoying a 
cup of coffee," "going downhill on a sled," or "playing airsoft [a team shooting sport comparable to paintball]," or in terms of supposedly imaginary experiences, such as "hunting with arrows because of the absence of arrow-damaging rocks."

Whereas the above-exemplified students' accounts of their surroundings and references to everyday experiences contained narrative elements (such as sequential events, agency, or purpose) or referred to everyday narratives, they cannot be defined as complete narratives per se (cf. Norris, Guilbert, Smith, Hakimelahi, and Phillips 2005). However, the students also used the narrative mode on a more direct level by contextualizing a science learning task in some narratives. The students accomplished the narrativization by positioning themselves in a part of the story, the structure of which was derived from both the task and stories from their everyday culture. For example, when they were finding mushrooms or invertebrates during different lessons in the forest, the students referred to a Pokémon mobile game-very popular at the time in Finland - in a way that paralleled their science learning task with playing the game. The discourse of finding very rare Pokémon in the game was used when students were finding some specimen, and they were thereby contextualizing the task in terms of the familiar game from their everyday lives. The following fragment exemplifies instances in which tasks were connected to everyday life in narrative form. The fragment starts in the middle of the bug-finding task, as Max starts to speak English while the group is heading toward a big rock, where the members hope to find invertebrates.

Fragment 3 (the underlined phrases were originally uttered in English instead of Finnish)

6 drink my own piss $($ ( laughter) $)$

Max: And we have been in the woods for two hours (.) and I'm going to

Mark: I have to find a (.) what what was it (.) I should find a (.) fuck I can't remember that one word fuck that he always says (.) reliable water source

10 Max: ((laughter)) yeah

11 Mark: ((laughter)) fuck he's such a slaggy guy Mark: we have to find something to eat so we can survive $\cdots$

26 Mark: yeah (..) some Bear Grylls wouldn't make it (.) Bear Grylls would make it in every place (.) but fuck he wouldn't make it in Finland 
In turn 5, Max uses English in the middle of the otherwise Finnish dialogue (with the exception of a few single English words, such as "very rare," referring to the Pokémon game). As Mark also continues in English, using the same person and structure as Max ("and so we're..."), it sounds as if he picked up something that he had heard and expanded it. Referring to trying to find something to eat conflicts with what the students are really trying but is not explained explicitly by Mark. Mark's laughter can be heard as if Max's utterance in English had been an invitation to laugh or a joke that is now responded to and expanded by Mark. Max's utterance (still in English) about being in the woods for two hours can then be heard as a further expansion of dialogue that now appears to have taken an imaginary sense. Like Mark's reference to finding food, Max's statement regarding two hours does not depict the real situation, as the students have been in the forest for no more than 10 min. Mark (turn 9) articulates the need to find a reliable water source, formulating in Finnish that he was looking for the English word, before completing the phrase. In the Finnish part of the utterance, a reference to an external person ("he") can be heard and is repeated soon thereafter (turn 11). Max's and Mark's laughter (turns 10 and 11) allow the noticing of the descriptions of the (at least somewhat) imaginary situation as both accepted by other students and humorous. Soon, Mark (turn 14) further expands the depiction by stating that finding something to eat is necessary for their survival. None of the students treated the story as unreal, as if they shared a common understanding within which "finding something to eat" or "drinking my own piss" make (humorous) sense. Where this understanding derives from is referred to as "he" (turns 9 and 11) and is indicated explicitly a moment later when Mark states that Bear Grylls (a British adventurer known for his survival TV series) would presumably survive anywhere but "wouldn't make it in Finland." The particular interactional resource shared by the students to enable them to understand each other with regard to "survival" in the woods reveals their common familiarity with the adventurer and television presenter.

The students talk about the television presenter in English and in ways that can be deemed as imitating him, at times even using a British/Irish accent. The students thereby refer to the narrative of survival that Bear Grylls has presented in his popular series. They produce parallels with their task of finding bugs for science learning and the task of survival "in the woods," which would be the content of the TV series. After the narrative has been established (Fragment 1), the students-mostly Mark and Max but occasionally joined by the others as well — continue to narrate the story on several occasions both when finding bugs and moving through the forest (e.g., "finding protein" or "finding shelter"), or they comment on how the things that Bear Grylls (more or less authentically) does compare to surviving in the Finnish woods (e.g., "hunting brown hears bare handed"). Through the imagination of their story, the task of science learning is contextualized narratively in a form and content that students are familiar with from their everyday lives. However, the students also separate and distance the actual learning task and their being in the forest from the popular culture survival narrative. The students criticize the authenticity and credibility of some of Bear Gryll's adventures (e.g., whether he really slept inside a dead camel and whether the fact that he found some food had been prearranged), and by making comparisons with their current surroundings, they communicate the perception that what they are currently experiencing might be more authentic than what is shown on the television, despite all the similarities with their narrated story.

All the while maintaining the survival narrative, the students complete their task of observing, finding, and identifying invertebrates. The following fragment shows how 
the survival narrative, now arising from an encounter with a muddy spot along the path, instantly changes into task-related talk.

Fragment 4

Mark: holy shit (.) if you fall down you'll get boots of [shit]

$\underline{\text { [you'll get AIDS if you fall down }}$

there ( (laughter))

Mark: ((laughter)) it's very contagious (.) you'll get AIDS and ten unknown STDS

(.) ((bends over toward a mushroom))

do we accept mushrooms? No we don't

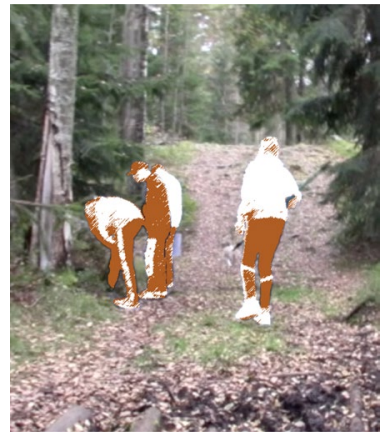

Mark and Max are crossing the muddy spot, walking along the logs ("this dangerous bridge"), while Tom and Jeff are going around the mud ("too far away" for Mark and Max). Mark describes the risk of falling down as getting "boots of shit," to which Max adds getting "AIDS." Max's laughter can be heard as an invitation to hear the utterance as a joke. This is accepted by Mark in his next turn, as evidenced by his laughter, repetition, and the addition of "ten unknown STDs" (the function of grotesque humor and exaggeration in contextualizing the science learning was addressed in more detail in the previous subsection). The narrative stops when Mark notices a mushroom that Max has already bent over to observe (offprint, turn 51) and addresses it with a task-related question for which he also immediately provides the answer ("Do we accept mushrooms? No, we don't"). The narrative is discontinued for a moment, as Mark goes to see whether Tom has caught any bugs with his net tool. They find a spider.

The previous examples show how the narrative contextualization of the learning task was temporarily integrated into the completion of the learning tasks. The inspiration for the narrative contextualization derived from the structure of the task, from the physical environment or the familiar cultural resources, or from all of them at the same time. In any case, it is the student who spontaneously draws on the narrative form despite any explicit requirement to do so. The narratives were not especially used to communicate science nor scientific concepts, as was suggested would be useful in science teaching (Avraamidou and Osborne 2009; Bruner 2004). Instead, the function of narratives was to connect the process of learning to everyday life: the use of narratives or narrative elements allowed students to interpret and constitute the science learning task as included in the cultural community of the students (Ricœur 1991). The paradigmatic mode of thought was represented by the scientific knowledge related to the completion of the tasks (Bruner 1986). However, the paradigmatic and narrative modes did not appear to exclude one another, but they coexisted temporarily as the students spontaneously contextualized the tasks within the narratives of the familiar lifeworld. 


\section{Discussion}

This study was designed to investigate the ways in which students connect in non-conceptual ways the experiences of their everyday world with science learning. Whereas the gap between everyday experiences and the presentation of (school) science has been recognized as a major problem disconnecting and alienating students from science and scientific careers (e.g., Barmby et al. 2008), science education research has approached this gap largely as a challenge arising in the learning of certain science concepts (e.g., Lidar et al. 2009). The present study examines culturally possible and intelligible ways in which students actually connect science learning processes to their everyday understandings. They do so by making connections that parallel those of a purely logical-conceptual nature. Using these non-conceptual means, the students draw on their familiar, fundamental bodily and cultural ways of relating to the world, and while completing their science tasks at the same time, they thereby contextualize science learning within their encompassing everyday understandings.

Our findings exemplify three specific forms of connections made with and related to the everyday world: (a) the bodily exploration of the physical environment; (b) grotesque, bodily humor as a way to temporarily overturn the seriousness of science learning; and (c) the contextualization of learning through narratives. Common to all of these forms is that each constitutes a fundamental mode of relating to and being rooted in the commonsense world. The premises of all understanding are of an experiential and bodily kind (Husserl 1989; James 1907), the authoritative and institutional cultural structures are relativized through referring them back to the material bodily principle that is manifested in the humorous and grotesque sense of life (Bakhtin 1984), and everyday cultural life is primarily represented and interpreted in narrative form (Bruner 1986; Ricœur 1983).

According to our findings, the bodily explorations, the material bodily principal manifested in the grotesque humor, and the narrative mode of thought connected students' scientific activities with everyday experiences on two levels: (a) the modes of relating to the environment, as well as contextualizing and interpreting the interactional situations in themselves, represented a fundamentally familiar, intuitive, and everyday way for students to position themselves in the world, and (b) the content of these connections - that is, the objects of the embodied experiments or the topics of the jokes of narratives - were derived from or inspired by both the scientific tasks in question and everyday cultural resources. This two-leveled nature of their evolving connections means that even if the content of the above-described forms of students' interaction would not have explicitly connected the everyday experiences with abstract science knowledge, these forms of interaction per se can support the connection with the fundamental everyday understandings, all the while participating in the science learning activity and repeatedly returning to the scientific task. Conversely, the same fundamental forms of relating to the world may also provide students with explicit possibilities to connect the conceptual (and procedural-e.g., making scientific observations) goals of the learning tasks with their familiar cultural resources and lifeworld. At times, these spontaneous ways of connecting also led to knowledge that was used explicitly in completing the current task (e.g., see Fragment 1). This merely shows that the knowledge acquired during the spontaneous activities that were seemingly unrelated to the current task could turn into meaningful knowledge not only in terms of connecting the everyday world with the world of science but also in terms of increased scientific understanding. This non-teleological direction of attaining new knowledge characterizes how primal experiences shape our understanding of the world and how scientific knowledge 
is layered and developed based on previous experiences (Husserl 1989). Accordingly, the non-teleological approach to science education foregrounds the students' possibilities of reliving the primal premises of historically formed abstract scientific idealizations (Roth 2015). The findings of this study exemplify how activities such as the spontaneous physical exploration of the environment (or other artifacts) may constitute fertile ground for subsequent scientific understandings although the activities themselves may initially appear to be off topic.

In science education, the bodily and affective dimensions of experiences are recognized as a significant part of learning (e.g., Roth and van Eijk 2010). Similarly, humor (Roth et al. 2011) and the grotesque (Weinstein and Broda 2009), as well as narratives (Avraamidou and Osborne 2009), have been acknowledged to be contributing aspects of science communication that are useful in instructional approaches. This study suggests that the nonintellectual dimensions may provide the means for students to make connections between their everyday sense of how the world works and the content of science even spontaneously without particular instructional encouragement. Accordingly, the findings show how these fundamental and primal forms of everyday understanding are used by students to spontaneously create third spaces in which the familiar cultural funds and scientific discourse (in the form of completing the task) converge in dialogic and meaningful ways (cf. Gutiérrez et al. 1999). Instructional approaches that are aimed at meaningful third spaces might benefit from not only acknowledging students' tendencies to make these non-cognitive connections but also providing possibilities for students to experiment freely with their diverse cultural resources during science tasks.

It is worth noting that the students' ways of contextualizing the learning activities through their everyday understandings did not always explicitly lead to those (canonical ones) promoted in science teaching. As one main goal of science education is learning science concepts and scientific ways of thinking, one could ask whether the demonstrated connections with fundamental everyday ways of understanding actually promote the learning of intellectual and conceptual content. However, the actual support for learning may lie elsewhere: The affective and bodily primal experience of the phenomena constitutes the fundamental premises for learning about it (Husserl 1989; Roth 2015). Thus, making an emotional-affective (bodily) engagement is a first step toward the motivated intellectual engagement, and supporting students as they make connections to their everyday experiences can also facilitate conceptual learning. In this study, it was the students themselves who chose how and when to draw on their everyday lives and the ways of understanding it. Both the connections with everyday life and the possibility of choices can be valuable factors in mitigating the alienating dimension of school science and providing possibilities for students to experience science learning in meaningful ways (cf. Bamberger and Tal 2006).

In this study, the students worked in an outdoor environment and generally out of the earshot of the teacher. The students repeatedly reported that the relatively distant recording had no effect on their interaction. Either way, the study focuses on cultural and interactional possibilities for students to use their everyday understandings of the world-not on the underlying reasons for these activities specific to the individuals. Whatever the individual reasons may be, the ways in which they are acted out in the interaction are primarily sociocultural and, thus, transcend the individual. We are reporting on cultural patterns that inherently transcend individual characteristics, which is a fact that also pertains to conceptual talk in and about science (Roth 2008). Whereas outdoor environments per se can offer particular potential for students' own explorations and meaningful interaction with a sense of freedom (Tal, Lavie Alon, and Morag 2014), in this study, the environment most importantly allowed the particular phenomena to become visible, thereby enabling them to be 
studied. However, the findings of the study are not limited to any particular setting. There are frequent suggestions in the literature advocating the use of instructional approaches that emphasize student-led activities, inquiries, and students' curiosity (e.g., Wu, Kuo, Wu, Jen, and Hsu 2018). Science inquiries allow students to interact bodily with the environment; likewise, the opportunities for social interaction, including joking and drawing on stories, are likely to increase when students are given more choice over the activities. Whereas the particular instructional approaches that promote bodily exploration, narratives, and the use of humor can certainly be valuable in supporting meaningful connections with everyday experiences, the findings of this study show that students also spontaneously draw on their cultural and bodily resources to make such connections, at least during openly structured science tasks.

Some of the observed joking and grotesque humor-as well as some narratives and bodily explorations-were such that they would likely not be possible in the direct presence of the teacher. For example, the expressions that related to culturally taboo themes about sexual organs or sexual intercourse are typically considered as swearing, which is restricted in society (Ljung 2011). At least in the classroom, some of the language that the students used would be chastised as off-topic activities or might trigger disciplinary action. It may be argued that the absence of the teacher afforded, for example, the grotesque humor to be used to relativize and overturn the seriousness of science learning. In this particular outdoor setting, the teacher was aware of the students' possible off-topic activities but recognized them as a potentially valuable positive experience of science learning and nature environment, while some structural and pedagogical choices allowed the general focus to remain on the tasks (Kervinen et al. 2018). However, similar possibilities for communication out of the earshot of the teacher arise in classrooms. One study showed that solely the placement of the teacher considerably influences the discourses in different locations in the classroom (Roth, McGinn, Woszczyna, and Boutonne 1999), and teachers are not generally aware of the conversational topics, which may not only be off topic but may also go as far as accusing peers of racism (e.g., Roth 2009). While we do not want to endorse the use of offensive language or jokes, this study accordingly shows that students can, for example, use questionable humor in their communication while working out of the earshot of the teacher. However, the findings of this study show that some of the activities that might be typically considered as off topic or even objectionable - but that can be abundant in the reality of classroom interactions - may have a function for students in connecting the learning activity with their everyday lifeworld in meaningful ways. Moreover, just like the carnival sense of life functioned as a temporal liberation from the official seriousness and limitations during medieval times (Bakhtin 1984), the students in this study continued with or returned to their original science task despite the temporal absence from or debasement of official science. In the sense that, for example, the grotesque joking functioned as a way to contextualize the task within everyday out-of-school life experiences, it had a double function: While humor overturned the seriousness of the science task, it simultaneously allowed the task to be relativized in a meaningful way and to be (seriously) continued (cf. Roth et al. 2011).

In this study, we analyzed materials gathered from a group of students who were not particularly interested in science. The phenomena we describe concerning the ways of making connections between science and everyday experiences may be particularly important to and more frequently observed in student groups with an academic focus. However, in other reported cases, the students were attending an academically oriented private school and subsequently went to study in STEM fields at the university level (Roth 2009). Future studies investigating the prevalence of the phenomena that we describe here may suggest 
that they occur more frequently among those who are traditionally less interested and lower-achieving in science. It would then be particularly important to concentrate on ways for less science-oriented (or school-oriented) students to make affectively meaningful connections between what is familiar to them and what they experience during science tasks.

Acknowledgements Open access funding provided by University of Helsinki including Helsinki University Central Hospital.

Open Access This article is licensed under a Creative Commons Attribution 4.0 International License, which permits use, sharing, adaptation, distribution and reproduction in any medium or format, as long as you give appropriate credit to the original author(s) and the source, provide a link to the Creative Commons licence, and indicate if changes were made. The images or other third party material in this article are included in the article's Creative Commons licence, unless indicated otherwise in a credit line to the material. If material is not included in the article's Creative Commons licence and your intended use is not permitted by statutory regulation or exceeds the permitted use, you will need to obtain permission directly from the copyright holder. To view a copy of this licence, visit http://creativecommons.org/licenses/by/4.0/.

\section{Appendix: Transcription conventions}

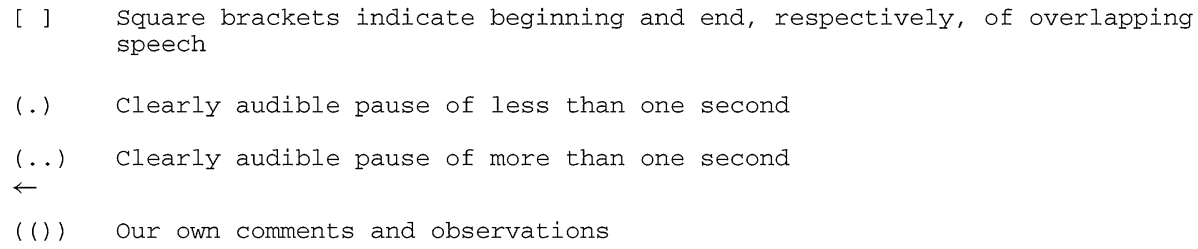

\section{References}

Aikenhead, G. S. (2001). Students' ease in crossing cultural borders into school science. Science Education, 85, 180-188. https://doi.org/10.1002/1098-237x(200103)85:2<180::aid-sce50>3.0.co;2-1.

Archer, L., DeWitt, J., Osborne, J., Dillon, J., Willis, B., \& Wong, B. (2010). "Doing" science versus "being" a scientist: Examining 10/11-year-old schoolchildren's constructions of science through the lens of identity. Science Education, 94, 617-639. https://doi.org/10.1002/sce.20399.

Avraamidou, L., \& Osborne, J. (2009). The role of narrative in communicating science. International Journal of Science Education, 31, 1683-1707. https://doi.org/10.1080/09500690802380695.

Bakhtin, M. (1981). The dialogic imagination, trans. Austin, TX: University of Texas Press.

Bakhtin, M. M. (1984). Rabelais and his world. Bloomington, IN: Indiana University Press.

Bamberger, Y., \& Tal, T. (2006). Learning in a personal context: Levels of choice in a free choice learning environment in science and natural history museums. Science Education, 91, 75-95. https://doi. org/10.1002/sce.20174.

Barmby, P., Kind, P. M., \& Jones, K. (2008). Examining changing attitudes in secondary school science. International Journal of Science Education, 30, 1075-1093. https://doi.org/10.1080/0950069070 1344966.

Barton, A. C., \& Tan, E. (2009). Funds of knowledge and discourses and hybrid space. Journal of Research in Science Teaching, 46, 50-73. https://doi.org/10.1002/tea.20269.

Berge, M. (2017). The role of humor in learning physics: A study of undergraduate students. Research in Science Education, 47, 427-450. https://doi.org/10.1007/s11165-015-9508-4.

Bruner, J. (1986). Actual minds, possible worlds. Cambridge, MA: Harvard University Press. 
Bruner, J. (2004). Narratives of science. In E. Scanlon, P. Murphy, J. Thomas, \& E. Whitelegg (Eds.), Reconsidering science learning (pp. 90-98). London: Routledge Falmer.

Dewey, J. (2008). Later works vol. 10: Art as experience. Carbondale, IL: Southern Illinois University Press. (Original work published in 1934).

Finnish National Board of Education (FNBE) (2016). National Core Curriculum for Basic Education 2014. Helsinki, Finland: Finnish National Board of Education.

Fleer, M. (2009). Understanding the dialectical relations between everyday concepts and scientific concepts within play-based programs. Research in Science Education, 39, 281-306. https://doi.org/10.1007/ s11165-008-9085-X.

Garfinkel, H., \& Sacks, H. (1986). On formal structures of practical action. In H. Garfinkel (Ed.), Ethnomethodological studies of work (pp. 160-193). London: Routledge \& Kegan Paul.

Gilbert, G. N., \& Mulkay, M. (1984). Opening Pandora's box: A sociological analysis of scientists' discourse. Cambridge: Cambridge University Press.

Gutiérrez, K. D., Baquedano-López, P., \& Tejeda, C. (1999). Rethinking diversity: Hybridity and hybrid language practices in the third space. Mind, Culture, and Activity, 6, 286-303. https://doi. org/10.1080/10749039909524733.

Husserl, E. (1976). Husserliana Gesammelte Werke Band VI: Die Krisis der europäischen Wissenschaften und die transzendentale Phänomenologie. Eine Einleitung in die phänomenologische Philosophie [Husserliana collected works vol. 6: The crisis of the European sciences and transcendental phenomenology: An introduction to phenomenological philosophy]. The Hague: Martinus Nijhoff.

Husserl, E. (1989). The origin of geometry. In J. Derrida (Ed.), Edmund Husserl's Origin of Geometry: An introduction (pp. 155-180). Lincoln, NE: University of Nebraska Press.

James, W. (1907). Pragmatism: A new name for some old ways of thinking. New York: Longmans, Green.

Jefferson, G. (1979). A technique for inviting laughter and its subsequent acceptance/declination. In G. Psathas (Ed.), Everyday language: Studies in ethnomethodology (pp. 79-96). New York: Irvington.

Jordan, B., \& Henderson, A. (1995). Interaction analysis: Foundations and practice. Journal of the Learning Sciences, 4, 39-103. https://doi.org/10.1207/s15327809j1s0401_2.

Kervinen, A., Roth, W.-M., Juuti, K., \& Uitto, A. (2020). "How stupid can a person be?" - Students coping with authoritative dimensions of science lessons. Learning, Culture and Social Interaction. https://doi.org/10.1016/j.1csi.2019.100367.

Kervinen, A., Uitto, A., \& Juuti, K. (2018). How fieldwork-oriented biology teachers establish formal outdoor education practices. Journal of Biological Education. https://doi.org/10.1080/00219 266.2018.1546762.

Kilbourne, E. D. (1996). Humor in science. Proceedings of the American Philosophical Society, 140, 338-349.

Lidar, M., Almqvist, J., \& Östman, L. (2009). A pragmatist approach to meaning making in children's discussions about gravity and the shape of the earth. Science Education, 94, 689-709. https://doi. org/10.1002/sce.20384.

Ljung, M. (2011). Swearing: A cross-cultural linguistic study. Houndmills, Basingstoke: Palgrave MacMillan. https://doi.org/10.1057/9780230292376.

Moje, E. B., Ciechanowski, K. M., Kramer, K., Ellis, L., Carrillo, R., \& Collazo, T. (2004). Working toward third space in content area literacy: An examination of everyday funds of knowledge and discourse. Reading Research Quarterly, 39, 38-70. https://doi.org/10.1598/rrq.39.1.4.

Mutonyi, H. (2016). Stories, proverbs, and anecdotes as scaffolds for learning science concepts. Journal of Research in Science Teaching, 53, 943-971. https://doi.org/10.1002/tea.21255.

$\mathrm{Na}$, J., \& Song, J. (2014). Why everyday experience? Interpreting primary students' science discourse from the perspective of John Dewey. Science \& Education, 23, 1031-1049. https://doi.org/10.1007/ s11191-013-9637-y.

Norris, S. P., Guilbert, S. M., Smith, M. L., Hakimelahi, S., \& Phillips, L. M. (2005). A theoretical framework for narrative explanation in science. Science Education, 89, 535-563. https://doi. org/10.1002/sce.20063.

Phelan, P., Davidson, A. L., \& Cao, H. T. (1991). Students' multiple worlds: Negotiating the boundaries of family, peer, and school cultures. Anthropology \& Education Quarterly, 22(3), 224-249. https://doi. org/10.1525/aeq.1991.22.3.05x1051k.

Pugh, K. J., Bergstrom, C. M., \& Spencer, B. (2017). Profiles of transformative engagement: Identification, description, and relation to learning and instruction. Science Education, 101, 369-398. https:// doi.org/10.1002/sce.21270.

Ricœur, P. (1983). Time and narrative (Vol. 1). Chicago: University of Chicago Press.

Ricœur, P. (1991). From text to action: Essays in hermeneutics II. Evanston: Northwestern University Press. 
Roth, W.-M. (2005). Doing qualitative research: Praxis of methods. Rotterdam: Sense Publishers.

Roth, W.-M. (2008). The nature of scientific conceptions: A discursive psychological perspective. Educational Research Review, 3, 30-50. https://doi.org/10.1016/j.edurev.2007.10.002.

Roth, W.-M. (2009). Dialogism: A Bakhtinian perspective on science and learning. Rotterdam: Sense Publishers.

Roth, W.-M. (2013). Technology and science in classroom and interview talk with Swiss lower secondary school students: A Marxist sociological approach. Cultural Studies of Science Education, 8, 433-465. https://doi.org/10.1007/s11422-012-9473-4.

Roth, W.-M. (2015). Enracinement or the earth, the originary ark, does not move: On the phenomenological (historical and ontogenetic) origin of common and scientific sense and the genetic method of teaching (for) understanding. Cultural Studies of Science Education, 10, 469-494. https://doi. org/10.1007/s11422-014-9606-Z.

Roth, W.-M. (2019). Transactional psychology of education: Toward the social in a strong sense. Cham: Springer.

Roth, W.-M., \& Jornet, A. (2014). Toward a theory of experience. Science Education, 98, 106-126. https ://doi.org/10.1002/sce.21085.

Roth, W.-M., \& Jornet, A. (2017). Understanding educational psychology: A late Vygotskian, Spinozist approach. Dordrecht: Springer. https://doi.org/10.1007/978-3-319-39868-6.

Roth, W.-M., McGinn, M. K., Woszczyna, C., \& Boutonne, S. (1999). Differential participation during science conversations: The interaction of focal artifacts, social configurations, and physical arrangements. Journal of the Learning Sciences, 8, 293-347. https://doi.org/10.1207/s15327809j 1s0803\&4_1.

Roth, W.-M., Ritchie, S. M., Hudson, P., \& Mergard, V. (2011). A study of laughter in science lessons. Journal of Research in Science Teaching, 48, 437-458. https://doi.org/10.1002/tea.20412.

Roth, W.-M., \& van Eijck, M. (2010). Fullness of life as minimal unit: STEM learning across the life span. Science Education, 94, 1027-1048. https://doi.org/10.1002/sce.20401.

Selting, M., Auer, P., Barden, B., Bergmann, J., Couper-Kuhlen, E., Günthner, S., et al. (1998). Gesprächsanalytisches Transkriptionssystem (GAT) [Conversation-analytic system of transcriptions]. Linguistische Berichte, 173, 91-122.

Tal, T., Lavie Alon, N., \& Morag, O. (2014). Exemplary practices in field trips to natural environments. Journal of Research in Science Teaching, 51, 430-461. https://doi.org/10.1002/tea.21137.

Tsurusaki, B. K., Calabrese Barton, A., Tan, E., Koch, P., \& Contento, I. (2012). Using transformative boundary objects to create critical engagement in science: A case study. Science Education, 97, 1-31. https://doi.org/10.1002/sce.21037.

Uitto, A., Juuti, K., Lavonen, J., \& Meisalo, V. (2006). Students' interest in biology and their out-ofschool experiences. Journal of Biological Education, 40, 124-129. https://doi.org/10.1080/00219 266.2006.9656029.

van Eijck, M., \& Roth, W. M. (2011). Cultural diversity in science education through novelization: Against the epicization of science and cultural centralization. Journal of Research in Science Teaching, 48(7), 824-847. https://doi.org/10.1002/tea.20422.

Vološinov, V. N. (1973). Marxism and the philosophy of language. Cambridge, MA: Harvard University Press.

Vosniadou, S., Vamvakoussi, X., \& Skopeliti, I. (2008). The framework theory approach to the problem of conceptual change. In S. Vosniadou (Ed.), International handbook of research on conceptual change (pp. 3-34). New York: Routledge.

Vygotsky, L. S. (1978). Mind in society: The development of higher psychological processes. Cambridge, MA: Harvard University Press.

Wallace, C. S. (2004). Framing new research in science literacy and language use: Authenticity, multiple discourses, and the "Third Space". Science Education, 88, 901-914. https://doi.org/10.1002/sce.20024.

Weinstein, M., \& Broda, M. (2009). Resuscitating the critical in the biological grotesque: Blood, guts, biomachismo in science/education and human guinea pig discourse. Cultural Studies of Science Education, 4, 761-780. https://doi.org/10.1007/s11422-009-9186-5.

Wu, P. H., Kuo, C. Y., Wu, H. K., Jen, T. H., \& Hsu, Y. S. (2018). Learning benefits of secondary school students' inquiry-related curiosity: A cross-grade comparison of the relationships among learning experiences, curiosity, engagement, and inquiry abilities. Science Education, 102, 917-950. https://doi. org/10.1002/sce.21456.

Publisher's Note Springer Nature remains neutral with regard to jurisdictional claims in published maps and institutional affiliations. 
Anttoni Kervinen is a doctoral student in the Faculty of Educational Sciences in the University of Helsinki. He has master's degree in biology education. His research focuses on teaching and learning biology in outdoor settings and teacher professional development in science teaching.

Wolff-Michael Roth is Lansdowne Professor of Applied Cognitive Science. His research focuses on knowing and learning across the lifespan in formal and informal learning environments (e.g. workplace, activism). The work is transdisciplinary and is published outlets of very different scholarly communities. His recent work includes the books Transactional Psychology of Education: Toward a Strong Version of the Social (2019), Dwelling, Building, Thinking: A Post-Constructivist Perspective on Education, Learning, and Development (2018), and, with A. Jornet, Understanding Educational Psychology: A Late Vygotskian, Spinozist Approach (2017).

Kalle Juuti is Associate Professor of Digital Learning at Schools. He was science teacher educator over decade and he was a vice leader of class teacher education programme and subject teacher education programme. His research interests are student engagement in science, digital tools in science teaching and learning, education for sustainability, and teachers' professional learning.

Anna Uitto is Professor in Biology Education in the Faculty of Educational Sciences in the University of Helsinki, Finland. Her research interest include conceptual understanding and inquiry-based approach in biology education, outdoor and biodiversity education, socio-scientific issues and education for sustainable developent, especially in primary and secondary education and in teacher education. 